\title{
Effect of Constant and Fluctuating Temperatures on Resting and Active Oxygen Consumption of Toads, Bufo boreas
}

\author{
Cynthia Carey ${ }^{1}$ \\ Division of Biological Sciences, University of Michigan, Ann Arbor, Michigan 48109, USA
}

\begin{abstract}
Summary. The relations of standard and active rates of oxygen consumption to body temperature $\left(\mathrm{T}_{\mathrm{b}}\right)$ were tested in montane Bufo b. boreas and lowland Bufo boreas halophilus acclimated to constant $T_{\mathrm{b}}$ of 10,20 , or $30^{\circ} \mathrm{C}$ or to a fluctuating cycle of $5-30^{\circ} \mathrm{C}$. Standard metabolic rates (SMR) of boreas acclimated to $30^{\circ} \mathrm{C}$ and halophilus acclimated to $10^{\circ} \mathrm{C}$ show pronounced regions of thermal independence but all other standard and active metabolic rates of groups acclimated to other thermal regimes are thermally sensitive. The SMR of both subspecies acclimated to the $5-30^{\circ} \mathrm{C}$ cycle are more thermally sensitive than those of similar individuals acclimated to constant $T_{\mathrm{b}}$. In cases where the relation between SMR and $T_{\mathrm{b}}$ is linear for both halophilus and boreas at the same acclimation temperature, the slope and $\mathrm{Q}_{10}$ of the relation for boreas are significantly higher than those of halophilus. Acclimation had little or no effect on the active metabolic rates of either subspecies. The relation between SMR and $T_{\mathrm{b}}$ of boreas maintained under field conditions (Carey, 1979) is matched only by those of individuals from the same population acclimated to $20^{\circ} \mathrm{C}$.
\end{abstract}

\section{Introduction}

Over the past several decades numerous studies have focused on physiological responses to variation in body temperature $\left(T_{\mathrm{b}}\right)$ in ectothermic animals. In recognition of the fact that previous thermal history can influence metabolic responses to temperature (Bullock, 1955; Fromm and Johnson, 1955), most studies have acclimated the experimental animals to constant temperature in the laboratory prior to testing. The results from these procedures have revealed a variety of acclimatory patterns (see Prosser, 1973) from which few generaliza-

\footnotetext{
1 Present address: Department of EPO Biology, University of Colorado, Boulder, Colorado
} 80309, USA 
tions have emerged (Wieser, 1973). Many authors have attempted to predict from such acclimatory data how their experimental species would respond to temperature in the field (Tashian and Ray, 1957; Dunlap, 1969, 1971, 1972; Fitzpatrick et al., 1971; Packard, 1971; Fitzpatrick and Atebara, 1974). If previous thermal history can indeed influence physiological responses to temperature, such predictions probably become less accurate the more the thermal acclimatory regime deviates from the actual $T_{\mathrm{b}}$ of the animals in the field. Since most ectothermic animals experience some daily and seasonal variation in $T_{\mathrm{b}}$ due to fluctuations of their thermal environment or to behavioral choice (Barlow, 1958; Brett, 1971), it is reasonable to ask if an animal with variable $T_{\mathrm{b}}$ in its recent thermal history would respond differently to variation in $T_{\mathrm{b}}$ than in those maintained at constant $T_{\mathrm{b}}$.

Therefore, the purpose of this study was to measure standard and active rates of oxygen consumption of individuals maintained on constant or fluctuating thermal regimes and to compare these results with those reported elsewhere for similar individuals maintained under field conditions (Carey, 1979). Resting and active levels of oxygen consumption were studied since often these processes are temperature-dependent and exhibit acclimation in many ectothermic animals (see Prosser, 1973), Montane Bufo b. boreas and lowland Bufo boreas halophilus were used because they represent ectothermic species which are voluntarily active over different temperature spans. Body temperatures of Bufo b. boreas can vary $30^{\circ} \mathrm{C}$ daily, whereas Bufo boreas halophilus are characteristically active over a temperature range no greater than $20^{\circ} \mathrm{C}$ (Carey, 1978). In the subsequent discussion, "boreas" will designate the nominate subspecies, Bufo b. boreas, and "halophilus" will indicate the subspecies Bufo boreas halophilus.

\section{Materials and Methods}

Sixty boreas (mean mass $=47.3 \mathrm{~g}$ ) were captured near the Rocky Mountain Biological Laboratory, Gothic, Gunnison County, Colorado at altitudes between 2900 and $3100 \mathrm{~m}$ between June and August. Seventy halophilus (mean mass $=57.8 \mathrm{~g}$ ) were collected at the Devil's Gate Reservoir, La Canada, Los Angeles County, California in February and March. The toads were transported in styrofoam containers by truck or air to the University of Michigan where they were divided randomly into groups for acclimation to different temperature regimes. Three groups were placed in cabinets set at constant temperatures $\left(11,22\right.$ and $\left.34^{\circ} \mathrm{C}\right)$ so that body temperatures of the toads approximated 10,20 and $30\left( \pm 0.5^{\circ} \mathrm{C}\right)$. Fluorescent lights in each chamber provided a $12-\mathrm{h}$ photoperiod. A fourth group of both species was housed in a Forma Scientific Model 13 growth chamber providing a 12-h cycle of photoperiod and air temperature between 5 and $30^{\circ} \mathrm{C}$ (Fig. 1). The periods of heating and cooling in the cycle required about 1 to $1 \frac{1}{2} \mathrm{~h}$ each. Deep body temperatures of a $45-\mathrm{g}$ toad, as measured by a 35 ga copper-constantan thermocouple connected to a Honeywell multi-point potentiometer, lagged slightly behind heating and cooling of the air. Because of the high humidity and lack of convection in the Forma Scientific chamber, $T_{\mathrm{b}}$ of toads approximated air temperatures $\left(+0.2^{\circ} \mathrm{C}\right)$ once the appropriate end point $\left(5\right.$ or $30^{\circ} \mathrm{C}$ ) was reached.

Toads were fed Tenebrio larvae or house crickets several times weekly, depending on the temperature of acclimation. Toads at $30^{\circ} \mathrm{C}$ were fed about triple the frequency of toads at $10^{\circ} \mathrm{C}$. The insects were force-fed to toads acclimated to $10^{\circ} \mathrm{C}$ because cold immobilized the prey. Each toad was fasted four days before testing.

Rates of active and standard oxygen consumption were measured in the closed system described previously (Carey, 1979). Measurements were conducted in March-May and June-August for halo- 
Fig. 1. Pattern of the 24-h cycle of ambient temperatures $\left(T_{a}\right)$ and body temperatures $\left(T_{\mathrm{b}}\right)$ of a $45-\mathrm{g} B . b$. boreas in a Forma Scientific Model 13 growth chamber

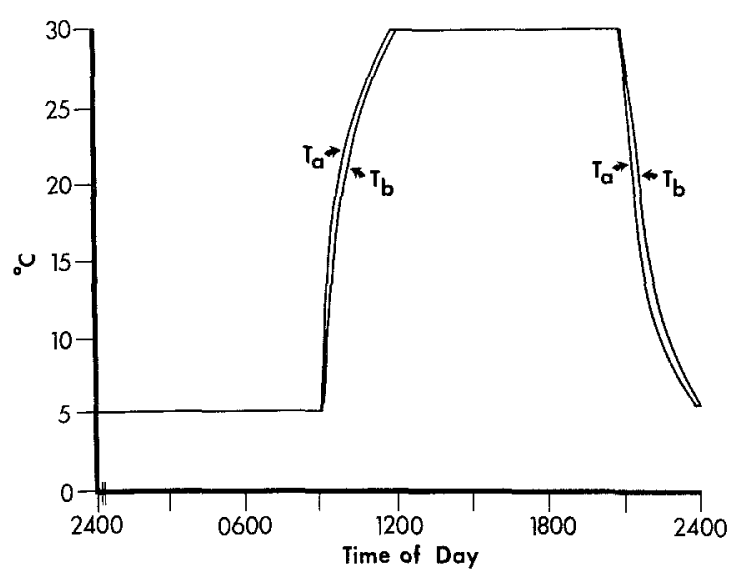

philus and boreas, respectively. These months coincided with the three months following breeding in the annual cycle of each group. Linear or polynomial regressions were used to describe logarithmically transformed data. One-way analysis of covariance was used to test for equality of intercepts and slopes of linear regressions, but polynomial regressions were not statistically compared due to lack of suitable tests.

\section{Results}

The relations of standard and active rates of oxygen consumption $\left(\dot{V}_{\mathrm{O}_{2}}\right)$ to body temperatures of boreas and halophilus acclimated to constant or fluctuating temperatures are represented in Figs. 2 and 3. The standard metabolic rates (SMR) of boreas acclimated to $30^{\circ} \mathrm{C}$ and halophilus acclimated to $10^{\circ} \mathrm{C}$ exhibit regions of pronounced thermal independence. However, standard values of toads acclimated to other thermal regimes show a direct relation to body temperature over the range of $T_{\mathrm{b}}$ tested. The thermal sensitivity of the active metabolic rates (AMR) of toads acclimated to all regimes decreased at higher $T_{\mathrm{b}}$.

The effect of acclimation on the SMR of many ectotherms has been described by changes in thermal sensitivity (the slope of the rate-temperature curve or line describing the relation of SMR to body temperature) or in the relative intensity of the SMR (a shift in the position of the intercept of the rate-temperature curve), or a combination of the two effects (see Prosser, 1973, for details). Statistical comparison of the slopes and intercepts of the regression lines defining the relation of metabolism to temperature thus provides a suitable measure for assessing the effect of acclimation in these toads.

The equations best describing the relation of SMR and AMR to body temperature of boreas and halophilus are presented in Table 1. The slopes of the linear regressions describing the relation of SMR of boreas acclimated to 10,20 , and $5-30^{\circ} \mathrm{C}$ (Eqs. 1,2 and 4$)$ differ significantly $(P<0.05)$ from one another. The intercepts of the equations for the SMR of boreas acclimated to 20 and $5-30^{\circ} \mathrm{C}$ (Eqs. 2 and 4) differ significantly from each other $(P<0.05)$. The relation of SMR to body temperature of boreas acclimated to $30^{\circ} \mathrm{C}$ clearly 

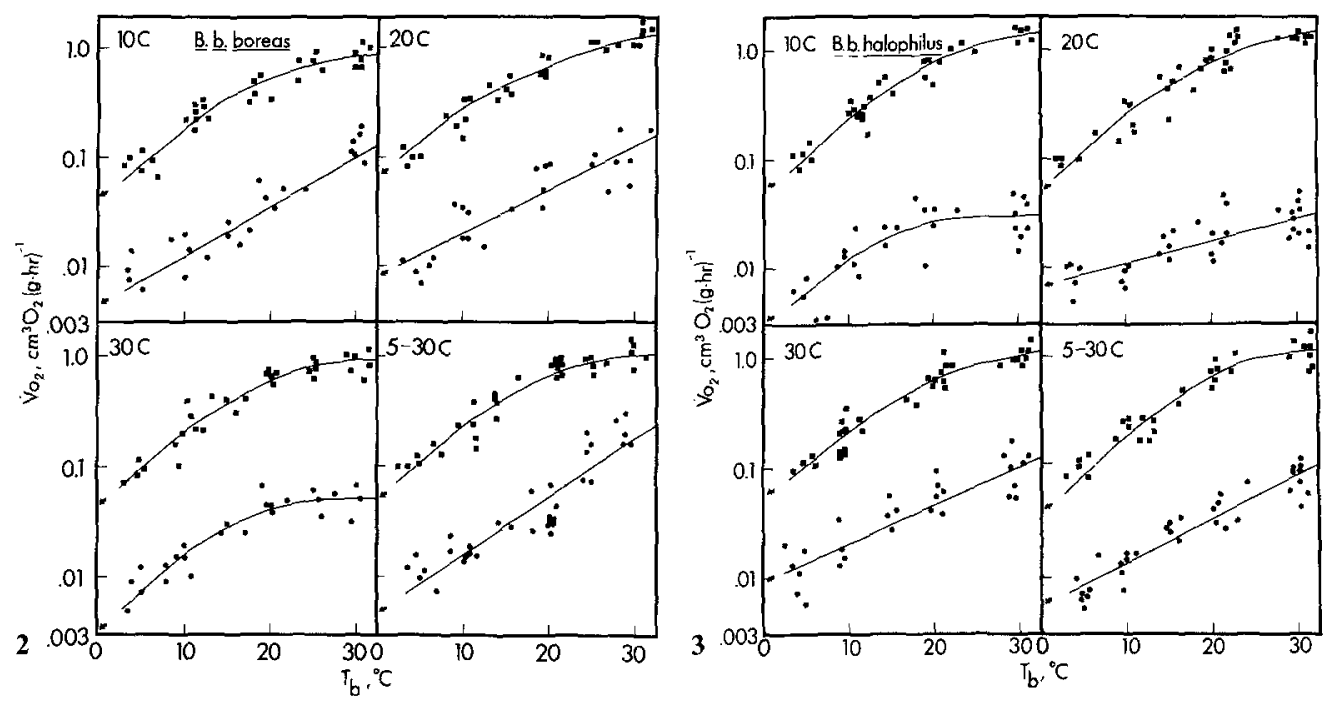

Fig. 2. The relation of standard (circles) and active (squares) oxygen consumption $\left(\dot{V}_{O_{2}}\right)$ to body temperature $\left(T_{\mathrm{b}}\right)$ in Bufo b. boreas acclimated to constant temperatures of 10,20 , or $30^{\circ} \mathrm{C}$, or a 12 -h cycle of $5-30^{\circ} \mathrm{C}$. Arrows indicate the intercept of the regression line with the ordinate. Regression lines are constructed on the basis of Eqs. 1-8. Data are plotted on a semilogarithmic grid. Resting values represent the mean of the two lowest hourly measurements. Active rates represent single measurements. $N=15$ at each acclimation temperature

Fig. 3. The relation of standard (circles) and active (squares) oxygen consumption $\left(\dot{V}_{\mathrm{O}_{2}}\right.$ ) to body temperature $\left(T_{\mathrm{b}}\right)$ in Bufo boreas halophilus acclimated to constant temperatures of 10,20 , or $30^{\circ} \mathrm{C}$, or a $12-\mathrm{h}$ cycle of $5-30^{\circ} \mathrm{C}$. Arrows indicate the intercept of the regression line with the ordinate. Regression lines are constructed on the basis of Eqs. 9-16. Data are plotted on semilogarithmic grid. Resting values represent the mean of the two lowest hourly measurements. Active rates represent single measurements. $N=17$ at each acclimation temperature

differs from those of boreas acclimated to other thermal regimes, but the equation for SMR of these toads at $30^{\circ} \mathrm{C}$ cannot be compared statistically with the linear regressions for SMR of the toads acclimated to other temperatures due to its polynomial nature. The slopes and corresponding values for $\mathrm{Q}_{10}$ calculated over the range of $0-30^{\circ} \mathrm{C}$ (Table 2) are greater for the SMR of boreas acclimated to the fluctuating cycle of $5-30^{\circ} \mathrm{C}$ than those of toads acclimated to constant temperatures.

The slopes and intercepts of the equations relating SMR to body temperature in halophilus acclimated to 20,30 , and $5-30^{\circ} \mathrm{C}$ (Eqs. 10, 11 and 12) differ significantly $(P<0.05)$ with the exception that the slopes of Eqs. 11 and 12 for the SMR of halophilus acclimated to 30 and $5-30^{\circ} \mathrm{C}$ were similar. The effect of acclimation to $10^{\circ} \mathrm{C}$ on the SMR of halophilus is clearly different from that of the other acclimation temperatures, due to the broad plateau of thermal independence. The corresponding values for $\mathrm{Q}_{10}$ calculated over the range of $0-30^{\circ} \mathrm{C}$ (Table 2) are greater for the SMR of halophilus acclimated to the fluctuating cycle of $5-30^{\circ} \mathrm{C}$ than those of toads acclimated to constant temperatures. 
Table 1. Equations for least squares regressions defining the relation of standard metabolic rate (SMR) and active metabolic rate (AMR) to body temperature in Bufo b. boreas and Bufo boreas halophilus acclimated to constant temperatures of 10,20 , or $30^{\circ} \mathrm{C}$ or a $12-\mathrm{h}$ cycle of $5-30^{\circ} \mathrm{C}$. Oxygen consumption (SMR and AMR) is in $\mathrm{cm}^{3} \mathrm{O}_{2}(\mathrm{~g} \cdot \mathrm{h})^{-1}$ and body temperature $\left(T_{\mathrm{b}}\right)$ in degrees Celsius

Acclimation temperature

Bufo b. boreas

Resting

$10^{\circ} \mathrm{C}$

$\log \mathrm{SMR}=-2.35+0.047 T_{\mathrm{b}}$

$n=24, r=0.91, S_{\mathrm{yx}}=0.193, S_{\mathrm{b}}=0.004$

$20^{\circ} \mathrm{C}$

$\log \mathrm{SMR}=-2.09+0.039 T_{\mathrm{b}}$

$$
n=25, r=0.89, S_{\mathrm{yx}}=0.193, S_{\mathrm{b}}=0.004
$$

$30^{\circ} \mathrm{C}$

$\log \mathrm{SMR}=-2.49+0.085 T_{\mathrm{b}}-0.0015\left(T_{\mathrm{b}}\right)^{2}$

$$
n=25, r=0.93, S_{\mathrm{yx}}=0.12
$$

$5-30^{\circ} \mathrm{C}$

$\log \mathrm{SMR}=-2.36+0.054 T_{\mathrm{b}}$

$n=34, r=0.92, S_{\mathrm{yx}}=0.185, S_{\mathrm{b}}=0.004$

Active

$$
\begin{aligned}
& 10^{\circ} \mathrm{C} \quad \log \mathrm{AMR}=-1.39+0.077 T_{\mathrm{b}}-0.0011\left(T_{\mathrm{b}}\right)^{2} \\
& n=30, r=0.95, S_{\mathrm{yx}}=0.11 \\
& 20^{\circ} \mathrm{C} \quad \log \mathrm{AMR}=-1.20+0.067 T_{\mathrm{b}}-0.0008\left(T_{\mathrm{b}}\right)^{2} \\
& n=30, r=0.97, S_{\mathrm{yx}}=0.084 \\
& 30^{\circ} \mathrm{C} \quad \log \mathrm{AMR}=-1.36+0.081-0.0012\left(T_{\mathrm{b}}\right)^{2} \\
& n=31, r=0.95, S_{\mathrm{yx}}=0.11 \\
& n=34, r=0.94, S_{\mathrm{yx}}=0.12
\end{aligned}
$$

Bufo boreas halophilus

Resting

$$
\begin{aligned}
& 10^{\circ} \mathrm{C} \quad \log \mathrm{SMR}=-2.55+0.081 T_{\mathrm{b}}-0.0016\left(T_{\mathrm{b}}\right)^{2} \\
& n=28, r=0.75, S_{y x}=0.22 \\
& 20^{\circ} \mathrm{C} \quad \log \mathrm{SMR}=-2.16+0.021 T_{\mathrm{b}} \\
& n=33, r=0.75, S_{\mathrm{yx}}=0.17, S_{\mathrm{b}}=0.003 \\
& 30^{\circ} \mathrm{C} \quad \log \mathrm{SMR}=-2.03+0.036 T_{\mathrm{b}} \\
& n=28, r=0.88, S_{\mathrm{yx}}=0.18, S_{\mathrm{b}}=0.004 \\
& 5-30^{\circ} \mathrm{C} \quad \log \mathrm{SMR}=-2.26+0.039 \\
& n=34, r=0.93, S_{y x}=0.14, S_{\mathrm{b}}=0.003
\end{aligned}
$$

Active

$$
\begin{aligned}
& 10^{\circ} \mathrm{C} \quad \log \mathrm{AMR}=-1.32+0.082 T_{\mathrm{b}}-0.0011\left(T_{\mathrm{b}}\right)^{2} \\
& n=30, r=0.96, S_{y x}=0.10 \\
& 20^{\circ} \mathrm{C} \quad \log A M R=-1.30+0.081 T_{\mathrm{b}}-0.0011\left(T_{\mathrm{b}}\right)^{2} \\
& n=35, r=0.94, S_{\mathrm{yx}}=0.14 \\
& 30^{\circ} \mathrm{C} \quad \log \mathrm{AMR}=-1.29+0.073 T_{\mathrm{b}}-0.0009\left(T_{\mathrm{b}}\right)^{2} \\
& n=34, r=0.96, S_{\mathrm{yx}}=0.10 \\
& n=31, r=0.95, S_{y x}=0.12
\end{aligned}
$$


Table 2. $\mathrm{Q}_{10}$ values for the relation of standard and active oxygen consumption of Bufo b. boreas and Bufo boreas halophilus acclimated to constant temperatures of 10,20, or $30^{\circ} \mathrm{C}$ or a fluctuating cycle of $5-30^{\circ} \mathrm{C}$. The $\mathrm{Q}_{10}$ is constant for linear relations and therefore the values are presented for the interval $0-30^{\circ} \mathrm{C} . \mathrm{Q}_{10}$ values are calculated over $5^{\circ} \mathrm{C}$ intervals for relations best described by polynomial regression equations. Values are calculated on the basis of Eqs. 1-16.

\begin{tabular}{|c|c|c|c|c|c|c|}
\hline \multirow{2}{*}{$\begin{array}{l}\text { Acclimation } \\
\text { Temperature }\end{array}$} & \multicolumn{6}{|c|}{ Temperature interval $\left({ }^{\circ} \mathrm{C}\right)$} \\
\hline & $0-30$ & $5-10$ & $10-15$ & $15-20$ & $20-25$ & $25-30$ \\
\hline \multicolumn{7}{|l|}{ Bufo b. boreas } \\
\hline $10^{\circ} \mathrm{C}$ resting & 2.95 & & & & & \\
\hline $10^{\circ} \mathrm{C}$ active & & 3.76 & 3.12 & 2.30 & 1.86 & 1.45 \\
\hline $20^{\circ} \mathrm{C}$ resting & 2.44 & & & & & \\
\hline $20^{\circ} \mathrm{C}$ active & & 4.95 & 3.06 & 2.47 & 2.04 & 1.69 \\
\hline $30^{\circ} \mathrm{C}$ resting & & 4.10 & 3.06 & 2.14 & 1.42 & 1.07 \\
\hline $30^{\circ} \mathrm{C}$ active & & 4.41 & 3.27 & 2.51 & 1.85 & 1.39 \\
\hline $5-30^{\circ} \mathrm{C}$ resting & 3.46 & & & & & \\
\hline $5-30^{\circ} \mathrm{C}$ active & & 4.37 & 3.27 & 2.36 & 1.84 & 1.37 \\
\hline \multicolumn{7}{|c|}{ Bufo boreas halophilus } \\
\hline $10^{\circ} \mathrm{C}$ resting & & 3.66 & 2.56 & 1.80 & 1.16 & 1.00 \\
\hline $10^{\circ} \mathrm{C}$ active & & 4.35 & 3.67 & 2.65 & 2.15 & 1.64 \\
\hline $20^{\circ} \mathrm{C}$ resting & 1.62 & & & & & \\
\hline $20^{\circ} \mathrm{C}$ active & & 4.41 & 3.38 & 2.76 & 2.05 & 1.60 \\
\hline $30^{\circ} \mathrm{C}$ resting & 2.29 & & & & & \\
\hline $30^{\circ} \mathrm{C}$ active & & 4.00 & 3.30 & 2.56 & 2.11 & 1.74 \\
\hline $5-30^{\circ} \mathrm{C}$ resting & 2.45 & & & & & \\
\hline $5-30^{\circ} \mathrm{C}$ active & & 4.62 & 3.80 & 2.69 & 2.11 & 1.58 \\
\hline
\end{tabular}

The relation of SMR to body temperature of boreas may be statistically compared with those of halophilus acclimated to similar temperatures, where the relations for both groups are linear. Comparison of Eqs. 2 and 10 (SMR of boreas and halophilus acclimated to $20^{\circ} \mathrm{C}$ ) and Eqs. 4 and 12 (SMR of boreas and halophilus acclimated to $5-30^{\circ} \mathrm{C}$ ) indicates that the slopes and intercepts of each pair of equations differ significantly $(P<0.05)$. The slopes and $\mathrm{Q}_{10}$ for boreas are higher than the respective values for halophilus at both acclimation temperatures.

The effect of acclimation to various constant or fluctuating temperatures on rates of oxygen consumption of toads during vigorous exercise cannot be assessed statistically. The effect of acclimation on AMR appears to be minimal compared to the relative variation in the slopes and intercepts of the equations for SMR (Fig. 4) at various acclimation temperatures. Since most of the values for AMR used to calculate these polynomial regressions overlap considerably, the state of acclimation appears at most to be only a minor determinant of active metabolism in these two groups of toads.

The $\mathrm{Q}_{10}$ values for AMR calculated for $5^{\circ} \mathrm{C}$ intervals decrease continually with increasing body temperature in both boreas and halophilus acclimated to all thermal regimes (Table 2). In general, the $\mathrm{Q}_{10}$ of halophilus slightly exceed 


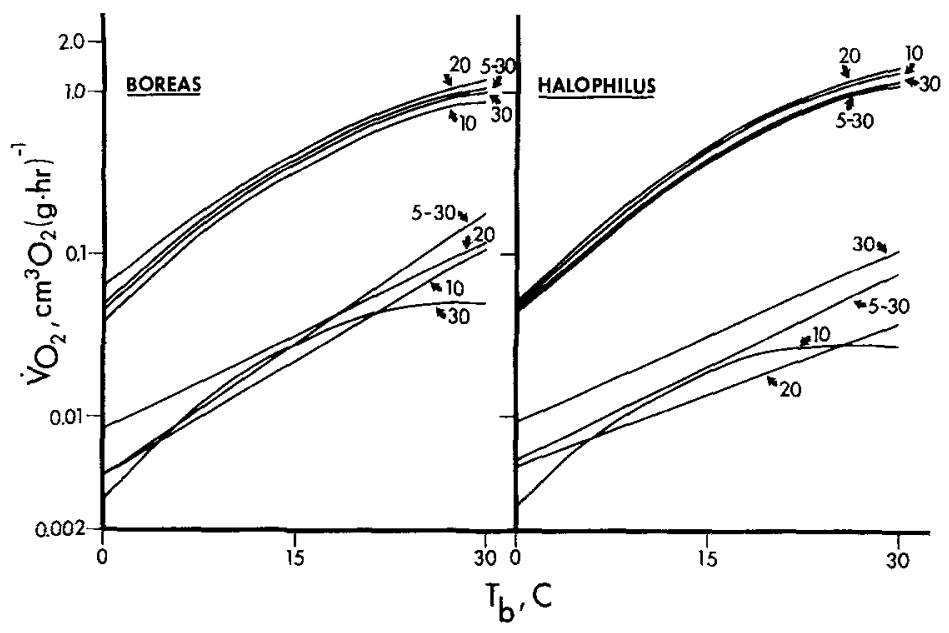

Fig. 4. Comparison of the relation of standard and active oxygen consumption $\left(\dot{V}_{\mathrm{O}_{2}}\right)$ to body temperature $\left(T_{\mathrm{b}}\right)$ in Bufo b. boreas and Bufo boreas halophilus acclimated to constant temperatures of 10,20 , or $30^{\circ} \mathrm{C}$, or a $12-\mathrm{h}$ cycle of $5-30^{\circ} \mathrm{C}$. Regression lines were calculated on the basis of Eqs. 1-8 (boreas) and Eqs. 9-16 (halophilus). Upper lines refer to active metabolic rates and lower lines to resting rates

those of boreas when the values are compared over the same temperature interval at the same acclimation temperature.

\section{Discussion}

The results of this study allow discussion of three main questions which will be considered separately: 1) does acclimation to constant or to cyclic thermal regimes result in different metabolic responses to $T_{\mathrm{b}}, 2$ ) can acclimatory regimes in the laboratory accurately reproduce metabolic patterns of individuals maintained under field conditions at the same season, and 3) what do metabolic responses to acclimatory regimes in the laboratory indicate about the mechanisms used by ectothermic animals for adjustment to short-term (daily or hourly) variation in $T_{\mathrm{b}}$ ?

Acclimation of both boreas and halophilus to $5-30^{\circ} \mathrm{C}$ produces relations of SMR to $T_{\mathrm{b}}$ that differ distinctly from those obtained from similar individuals acclimated to constant thermal conditions. The slopes and intercepts of the regression lines defining the relation of SMR to $T_{\mathrm{b}}$ for boreas acclimated to $5-30^{\circ} \mathrm{C}$ differ significantly from those of boreas acclimated to all constant temperatures, except for similar intercepts at $10^{\circ} \mathrm{C}$ and $5-30^{\circ} \mathrm{C}$. The intercepts and slopes of SMR of halophilus acclimated to $5-30^{\circ} \mathrm{C}$ differ significantly from those of other halophilus acclimated to constant temperatures with the exception that the slopes of the relations at $30^{\circ} \mathrm{C}$ and $5-30^{\circ} \mathrm{C}$ were similar. With this latter exception, the SMR of both boreas and halophilus acclimated to fluctuating conditions are characterized by greater thermal sensitivity and higher $Q_{10}$ than those of toads acclimated to constant conditions. 
So few studies have compared metabolic responses of ectotherms acclimated to constant and cyclic temperatures that no general patterns are apparent. The higher $\mathrm{Q}_{10}$ of SMR in toads acclimated to cyclic temperatures is certainly not universal. Metabolic rates of two species of intertidal crabs maintained on fluctuating temperatures have lower $Q_{10}$ than those maintained on constant regimes (Dame and Vernberg, 1978). Metabolic rates of spiders acclimated to cyclic temperatures do not differ in thermal sensitivity $\left(Q_{10}\right)$ from those of spiders on constant temperatures, but are about $35 \%$ higher over the entire range of $T_{\mathrm{b}}$ tested (Humphreys, 1975). Littoral mussels adapted to cyclic temperatures exhibit physiological rates which do not differ significantly from those of mussels acclimated to equivalent constant temperatures (Widdows, 1976).

It is clear that many different patterns of acclimatory adjustments to both constant (see Prosser, 1973) and fluctuating temperatures have been observed. In order to fully understand how ectothermic animals respond physiologically to variation in $T_{\mathrm{b}}$, it will ultimately be important to determine how much of this diversity is attributable to variability in metabolic strategies of ectothermic animals and how much is due to laboratory procedures producing artifactual results. Wieser (1977) has noted the possibility that imposing a constant thermal environment upon a species which normally experiences some variation in $T_{b}$ could introduce unknown factors into an experiment. One step in approaching this problem would be to determine how closely metabolic responses of ectotherms acclimated in the laboratory can approach those of similar individuals maintained under field conditions.

The regression equation best describing the relation of SMR of boreas maintained under field conditions is: $\log \mathrm{SMR}=-2.23+0.037 T_{\mathrm{b}}$ (Carey, 1979). The intercept and slope of this line differ significantly $(P<0.01)$ from those of all regression lines (Eqs. 1-4) describing the SMR of boreas acclimated in the laboratory to constant or fluctuating temperatures, with the exception that the slopes of the regression lines for field and $20^{\circ} \mathrm{C}$ data are similar. It is particularly interesting to note that the relations of SMR to $T_{\mathrm{b}}$ of boreas in the field and acclimated to $5-30^{\circ} \mathrm{C}$ are strikingly different, despite the similarities in daily range of $T_{\mathrm{b}}$ (Carey, 1978, 1979). These results suggest that the variability in thermal history is not the only determinant of the response of SMR to $T_{\mathrm{b}}$ in these toads. Other physical aspects of the laboratory environment differed from those in the field, such as the rate of change of $T_{\mathrm{b}}$, the predictability of change of $T_{\mathrm{b}}$, the length of photoperiod, and daily variation in the length of photoperiod. Numerous studies have documented that length of photoperiod can affect metabolic adjustments to temperature (Hoar, 1956; Roberts, 1964; Hutchison and Kohl, 1971; Turney and Hutchison, 1974; and others). Since ectotherms may use both length of photoperiod and daily body temperatures as cues for biochemical syntheses and metabolic recorganizations needed for survival under various seasonal conditions, acclimation to constant length of photoperiod or to a photoperiod which gives opposite cues to those of temperature (i.e. short photoperiod and warm temperatures and vice-versa) may produce metabolic patterns that are unrelated to those of the animals living in natural conditions, especially in high latitude organisms experiencing daily variation in photoperiod length. Further studies are undoubtedly necessary to explore 
the relation between metabolic rate and physical aspects of the environment, but the data reported herein suggest that extrapolation of laboratory data to predict how ectothermic animals respond metabolically to natural variation of $T_{\mathrm{b}}$ should be done with caution.

Finally, it is appropriate to consider what acclimatory patterns of metabolic rate can indicate about the mechanism of adjustment to thermal fluctuations in ectothermic animals. Laboratory studies have undoubtedly been useful in elucidating some of the long-term seasonal and evolutionary adjustments of ectotherms to warm or cold temperatures (Lagerspetz, 1977). Additionally, several studies have noted that amphibians with broad geographical ranges in the mid- to high-latitudes show greater acclimatory abilities than do neotropical animals experiencing restricted seasonal variation in $T_{\mathrm{b}}$ (Brattstrom, 1968, 1970; Feder, 1978). Snyder and Weathers (1975) have concluded that amphibians living in stable thermal environments might eventually lose abilities to adjust physiologically to thermal variation. These characteristics may only apply to terrestrial amphibians, since desert fishes collected from constant or fluctuating thermal environments show no differences in capacity to adjust the critical thermal maximum (CTM) (Brown and Feldmeth, 1971) and no correlation exists between acclimatory patterns and thermal diversity of habitat in marine polychaetes (Mangum, 1972).

Although acclimation experiments have undoubtedly been useful for identifying mechanisms of long-term adjustment to temperature, they may not provide much substantive evidence about mechanisms of short-term (daily or hourly) adjustment. Acclimatory changes observed on the whole-animal level (CTM or variation in metabolic rate) appear to require at least 2-4 days in amphibians (Brattstrom and Lawrence, 1962; Brattstrom, 1968; Dunlap, 1969). Molecular adjustments, including syntheses of new isozymes and components of cell membranes, can occur over a span of several weeks (see reviews by Prosser, 1967; Wieser, 1973). These time constants are too long to be effective in ectotherms experiencing broad and rapid variation in $T_{\mathrm{b}}$. This raises the question concerning how such animals not only regulate biochemical pathways, but also ensure that enzymes and cell components appropriate for each temperature within the range are available when required, particularly if variation in $T_{\mathrm{b}}$ is sudden and unpredictable.

Undoubtedly, these questions must ultimately be answered both on the biochemical and on the physiological levels. Wieser (1977) noted that the $V_{\max }$ of pyruvate kinase activity in the foot of Helix pomatia is perfectly compensated for the average temperature on the day on which the snail was collected and sacrificed. From these data he predicted that some ectothermic animals exposed to variable $T_{\mathrm{b}}$ might adjust to the estimated mean daily temperature, rather than to the extremes. Other data obtained on the whole-animal level indicates that the CTM of animals acclimated to cyclic temperatures more closely resemble those of similar individuals maintained on constant temperatures coinciding with the top of the daily cycle rather than with the average temperature of the cycle (Heath, 1963; Seibel, 1970; Hutchison and Ferrance, 1970). Additionally, acclimation to fluctuating thermal cycles increases the CTM and can provide a greater range of thermal tolerance in some ectotherms (Edney, 1964; Hubbs, 
1964; Lowe and Heath, 1969; Feldmeth et al., 1974). Perhaps these data indicate that whatever biochemical properties are necessary for survival at high temperatures are incorporated into the molecular adjustments to cyclic temperatures, rather than indicating that the animals are "acclimating" to the highest temperature of the cycle, as implied by some authors.

The data on CTM do not, of course, indicate anything about adjustments made for optimal function over the entire temperature span of the cycle. Unfortunately, the studies cited previously comparing metabolic rates of animals acclimated to constant or cyclic temperatures do not provide specific information on the nature of adjustment to thermal fluctuations. Additionally, the data presented here for SMR of boreas and halophilus do not add much new insight, either. Boreas are active daily over a $30^{\circ} \mathrm{C}$ range of $T_{\mathrm{b}}$, weather permitting, wherease halophilus are voluntarily active over only about a $15-20^{\circ} \mathrm{C}$ span during breeding and a much narrower range during the rest of their active season (Carey, 1978). The only appreciable difference between the SMR of boreas and halophilus at various acclimation temperatures is the greater thermal sensitivity of boreas at three acclimation temperatures. This pattern may relate to the possible importance of thermally sensitive metabolic rates in the montane environment (Carey, 1979). A confounding factor here is that acclimation had no effect on the AMR of either species (Fig. 4). Widdows (1973) has also noted that some functions do not show acclimation. Since AMR should principally reflect activities in metabolism of heart and skeletal tissues, it probably obliterates small difference in maintenance metabolism produced by acclimation. Since ectothermic animals are undoubtedly active at levels above standard metabolism much of the time in the field, the importance of acclimatory changes to activity at normal levels remains to be resolved.

In summary, acclimation to constant temperatures in many studies has undoubtedly contributed valuable information about the mechanism of long-term adjustment to thermal change in some ectotherms. However, acclimation to constant temperatures of animals normally experiencing daily variation in $T_{\mathrm{b}}$ may produce data which do not accurately answer the question concerning how such animals adjust to temperature in nature. The basic question concerning how ectothermic animals deal with thermal variation is far from being answered and fully merits further research, since such information is fundamental to understanding influences of the environment on energy procurement and expenditure in these animals.

Acknowledgements. This study was supported by NSF grant GB-41454 for support of doctoral research in the field sciences, The Theodore Roosevelt Memorial Fund of The American Museum of Natural History, NSF grant GB-25986 for the study of Systematics and Evolutionary Biology, and NSF grant BMS-75-03300 to W.R. Dawson, William R. Dawson graciously provided laboratory facilities, advice, and encouragement throughout this study. Laboratory facilities at the Rocky Mountain Biological Laboratory were provided by Dr. John C. Johnson, Jr. Critical comments on a previous draft of the manuscript were rendered by W.R. Dawson, B.E. Frye, C. Gans, and M.M. Martin.

\section{References}

Barlow, G.W.: Daily movements of desert pupfish, Cyprinodon macularius, in shore pools of the Salton Sea, California. Ecology 39, 580-587 (1958) 
Brattstrom, B.H.: Thermal acclimation in anuran amphibians as a function of latitude and altitude. Comp. Biochem. Physiol. 24, 93-111 (1968)

Brattstrom, B.H.: Thermal acclimation in Australian amphibians. Comp. Biochem. Physiol. 35, 69-103 (1970)

Brattstrom, B.H., Lawrence, P.: The rate of thermal acclimation in anuran amphibians. Physiol. Zool. 35, 148-156 (1962)

Brett, J.R.: Energetic responses of salmon to temperature. A study of some thermal relations in the physiology and fresh-water ecology of sockeye salmon (Oncorhynchus nerka). Am. Zool. 11, 99-113 (1971)

Brown, J.H., Feldmeth, C.R.: Evolution in constant and fluctuating environments: thermal tolerances of desert pupfish (Cyprinodon). Evolution 25, 390-398 (1971)

Bullock, T.H.: Compensation for temperature in the metabolism and activity of poikilotherms. Biol. Rev. 30, 311-342 (1955)

Carey, C.: Factors affecting body temperatures of toads. Oecologia (Berl.) 35, 197-219 (1978)

Carey, C.: Aerobic and anerobic energy expenditure during rest and activity in montane Bufo b. boreas and Rana pipiens. Oecologia 39, 213-228 (1979 b)

Dame, R.F., Vernberg, F.J.: The influence of constant and cyclic acclimation temperatures on the metabolic rates of Panopeus herbstii and Uca pugilator. Biol. Bull. 154, 188-197 (1978)

Dunlap, D.G.: Influence of temperature and duration of acclimation, time of day, sex and body weight on metabolic rates in the hylid frog, Acris crepitans. Comp. Biochem. Physiol. 31, $555-570(1969)$

Dunlap, D.G.: Latitudinal effects on metabolic rates in the cricket frog, Acris crepitans: Acutely measured rates in summer frogs. Biol. Bull. 143, 332-343 (1972)

Dunlap, D.G. : Latitudinal effects on metabolic rates in the frog, Acris crepitans: seasonal comparisons. Biol. Bull. 145, 103-118 (1973)

Edney, E.B.: Acclimation to temperature in terrestrial isopods. I. Lethal temperatures. Physiol. Zool. 37, 364-377 (1964)

Feder, M.E.: Environmental variability and thermal acclimation in neotropical and temperate zone salamanders. Physiol. Zool. 51, 7-16 (1978)

Feldmeth, C.R., Stone, E.A., Brown, J.H. : An increased scope for thermal tolerance upon acclimating pupfish (Cyprinodon) to cycling temperatures. J. comp. Physiol. 89, 39-44 (1974)

Fitzpatrick, L.C., Atebara, M.Y.: Effects of acclimation to seasonal temperatures on energy metabolism in the toad Bufo woodhousei. Physiol. Zool. 47, 119-129 (1974)

Fitzpatrick, L.C., Bristol, J.R., Stokes, R.M.: Thermal acclimation and metabolism in the Allegheny mountain salamander, Desmognathus ochrophaeus. Comp. Biochem. Physiol. 40A, 681-688 (1971)

Fromm, P.O., Johnson, R.E.: The respiratory metabolism of frogs as related to season. J. cell. comp. Physiol. 45, 343-359 (1955)

Heath, W.G.: Thermoperiodism in sea-run cutthroat trout (Samo clarki clarki) Science 142, 486-488 (1963)

Hoar, W.S.: Photoperiodism and thermal resistance of goldfish. Nature (Lond.) 178, 364-365 (1956)

Hubbs, C.: Effects of thermal fluctuations on the relative survival of greenthroat darter young from stenothermal and eurythermal waters. Ecology 45, 376-379 (1964)

Humphreys, W.F.: The respiration of Geolycosa godeffroyi (Araneae: Lycosidae) under conditions of constant and cyclic temperatures. Physiol. Zool. 48, 269-281 (1975)

Hutchison, V.H., Ferrance, M.R. : Thermal tolerances of Rana pipiens acclimated to daily temperature cycles. Herpetologica 26, 1-8 (1970)

Hutchison, V.H., Kohl, M.A.: The effect of photoperiod on daily rhythms of oxygen consumption in the tropical toad, Bufo marinus. Z. vergl. Physiol. 75, 367-382 (1971)

Lagerspetz, K.Y.H.: Interactions of season and temperature acclimation in the control of metabolism in Amphibia. J. Thermal Biology 2, 223-231 (1977)

Lowe, C.H., Heath, W.G.: Behavioral and physiological responses to temperature in the desert pupfish Cyprinodon macularius. Physiol. Zool. 42, 53-59 (1969)

Mangum, C.P.: Temperature sensitivity of metabolism in offshore and intertidal onuphid polychaetes. Mar. Biol. 17, 108-114 (1972)

Packard, G.C.: Oxygen consumption of montane and piedmont chorus frogs (Pseudacris triseriata): a study of evolutionary temperature compensation. Physiol. Zool. 44, 90-97 (1971)

Prosser, C.L.: Molecular mechanisms of temperature adaptation in relation to speciation. In: Molecu- 
lar mechanisms of temperature adaptation (C.L. Prosser, ed.), pp. 351--376. Washington, D.C.: American Association for the Advancement of Science 1967

Prosser, C.L.: Temperature. In: Comparative animal physiology, 3rd ed. (C.L. Prosser, ed.), pp. 362 428. Philadelphia: Saunders 1973

Prosser, C.L. : Physiological adaptations in animals. In: Physiological adaptation to the environment (F.J. Vernberg, ed.), pp. 3-18. New York: Intext Educational Publishers 1975

Roberts, J.L. : Metabolic responses of fresh-water sunfish to seasonal photoperiods and temperatures. Helgo. Wiss. Meersunter. 9, 459-473 (1964)

Seibel, R.V.: Variables affecting the critical thermal maximum of the leopard frog, Rana pipiens Schreber. Herpetologica 26, 208-213 (1970)

Snyder, G.K., W.W. Weathers: Temperature adaptations in amphibians. Am. Nat. 109, 93-101 (1975)

Tashian, R.E., Ray, C.: The relation of oxygen consumption to temperature in some tropical, temperate, and boreal anuran amphibians. Zoologica 42, $63-68$ (1957)

Turney, L.C., Hutchison, V.H.: Metabolic scope, oxygen debt, and diurnal oxygen consumption cycle of the leopard frog, Rana pipiens. Comp. Biochem. Physiol. 49 A, 583-601 (1974)

Widdows, J.: Effect of temperature and food on heart beat, ventilation rate and oxygen uptake of Mytilus edulis. Mar. Biol. 20, 269-276 (1973)

Widdows, J.: Physiological adapatation of Mytilus edulis to cyclic temperatures. J. comp. Physiol. 105, 115-128 (1976)

Wieser, W.: Temperature relations of ectotherms: a speculative review. In: Effects of temperature on ectothermic organisms (W. Wieser, ed.), pp. 1-23. Berlin-Heidelberg-New York: Springer 1973

Wieser, W. : Slow, fast- and medium fast responses of ectotherms to temperature changes: a new mechanism of metabolic compensation in Helix pomatia? J. Thermal Biology 2, 197-201 (1977)

Received December 11, 1978 